\title{
Design para inovação social na difusão do estilo de vida vegano
}

\section{Design for social innovation on the diffusion of the vegan lifestyle}

WEISS, Marco Antonio

Universidade Federal de Santa Catarina - UFSC I marcoweiss@outlook.com

CAVALCANTE, Ana Luisa Boavista Lustosa

Universidade Estadual de Londrina - UEL I anaboavista@gmail.com

FIGUEIREDO, Luiz Fernando Gonçalves de

Universidade Federal de Santa Catarina - UFSC I Iffigueiredo2009@gmail.com

\begin{abstract}
Resumo
Este artigo busca demonstrar, sistemicamente, uma proposta que possa viabilizar o acesso aos produtos veganos e difundir esse estilo de vida. Como procedimentos metodológicos, utilizou-se a pesquisa bibliográfica e o levantamento de dados de campo com a técnica de questionário e, por fim, foi construído um mapa sistêmico. Como resultado, propõe-se o conceito de organizações colaborativas, de Manzini (2008) em empreendimentos de produção de alimentos veganos, promovendo sua notoriedade e a consciência alimentar do estilo de vida vegano.
\end{abstract}

Palavras-chave: Veganismo. Inovação social. Organizações colaborativas. Gestão de design.

\section{Abstract}

This paper aims to describe, systemically, a proposal that can enable access to vegan products and spread this lifestyle. Methodological procedures include a bibliographical research and a field data collection with the application of a questionnaire. Finally, a systemic map was designed. As a result, the concept of collaborative organizations - described by Manzini (2008) - is proposed in vegan food production ventures, promoting their notoriety and the food awareness of the vegan lifestyle.

Keywords: Veganism. Social innovation. Collaborative organizations. Design management. 


\section{INTRODUC̣ÃO}

Esta pesquisa se origina com base nas dificuldades encontradas pelos consumidores de produtos e alimentos veganos na região de Toledo/Cascavel (Paraná) relacionadas ao acesso às informações a respeito de produtos, serviços, produtores e comerciantes deste tipo de produto. Outra questão que se apresenta é a dificuldade de compreensão de relevante parte da sociedade, em âmbito regional, do que se trata o veganismo e o porquê de alguém se tornar vegano. Assim, tal problema neste artigo, foi determinado como uma oportunidade de visualizar a troca de informações e produtos pelos atores envolvidos neste processo como organizações colaborativas.

O veganismo sugere uma aproximação com o conceito de sustentabilidade. O site Sociedade Vegana (VEGANISMO..., 2011) define que a ideia vegana está norteada na busca em "eliminar qualquer forma de exploração animal, não apenas na alimentação, como também no vestuário, em testes, na composição de produtos diversos, no trabalho, no entretenimento e no comércio". Este artigo apresenta um estudo a respeito do acesso aos produtos veganos, visando sistematizar informações sobre os produtos, produtores e fornecedores veganos neste contexto, identificando e contribuindo com os atores envolvidos (stakeholders') neste sistema de troca de informações, conhecimentos, produtos e serviços.

De acordo com Carus (2010), estudos apontados pela ONU no ano de 2010 relatam que o gás metano, responsável pela destruição da camada de ozônio e pelo efeito estufa, gerado na criação de gado no mundo corresponde a $19 \%$ do total emitido no mundo. A autora também menciona que a "agricultura, particularmente a carne e produtos derivados, é responsável por $70 \%$ do consumo mundial de água doce, 38\% do uso total de terras" (CARUS, 2010). A poluição é causada por vários motivos, na extração de matéria-prima, na produção industrial e na utilização dos bens de consumo, na eliminação de artefatos que perderam o valor econômico e emocional, assim como já descrito, na produção de alimentos. É um ciclo insustentável para o planeta. Dessa forma, é urgente a conscientização e o empenho de todas as partes envolvidas na produção, consumo e eliminação de produtos no desenvolvimento de soluções para a redução do impacto negativo das ações desenfreadas do ser humano

$1 \quad$ O termo stakeholder foi criado por um filósofo chamado Robert Edward Freeman. Ao entender a importância dos stakeholders, o responsável pelo planejamento ou plano consegue ter uma visão mais ampla de todos envolvidos em um processo ou projeto e saber de que maneira eles podem contribuir para a otimização deste. Os stakeholders são elementos fulcrais em termos de planejamento estratégico de uma empresa ou organização. Disponível em: http:// www.significados.com.br/stakeholder/. 
na natureza. Ao proporcionar um ambiente saudável para as atuais e futuras gerações melhoramos a qualidade da permanência humana e de outros seres vivos na Terra.

A questão norteadora desta pesquisa busca responder como possibilitar a interação entre os atores envolvidos (stakeholders) na produção e consumo dos produtos veganos locais e como apresentar uma plataforma colaborativa a esses atores com inovação social.

Para tanto, utilizou-se nos procedimentos metodológicos a pesquisa bibliográfica e o levantamento de dados de campo. Este último foi realizado por meio de três (03) tipos de questionários eletrônicos aplicados às pessoas adeptas do veganismo, produtores veganos e comerciantes de produtos veganos de diferentes regiões do Brasil. Em seguida, foram analisados os dados apresentados pelas pesquisas de campo, verificando-se os percentuais de respostas objetivas e sistematizando as principais respostas dissertativas em um quadro. Os dados e evidências encontrados direcionaram esta pesquisa ao desenvolvimento de um mapa de sistemas que demonstra, em uma visão holística, o inter-relacionamento entre os atores envolvidos no contexto de produção e consumo de produtos veganos que pode se tornar mais colaborativo e interativo, produzindo em desdobramento futuro um processo de inovação social.

O objetivo geral deste artigo, portanto, é oferecer uma proposta que possa viabilizar o acesso aos produtos veganos e difundir esse estilo de vida, atendendo às necessidades do público de acordo com as premissas de sustentabilidade e inovação social. Os objetivos específicos são elaborar um mapa sistêmico com os atores envolvidos na produção e comércio de produtos veganos; proporcionar visibilidade e valorização aos produtos veganos locais; e possibilitar a conscientização sobre os benefícios da alimentação vegana.

$\mathrm{Na}$ busca de alcançar tais objetivos, tem-se como pressuposto que o design para a sustentabilidade e a inovação social em um modelo de serviço voltado ao público vegano/vegetariano poderá, além de difundir o conhecimento sobre este estilo de vida, facilitar o acesso a esse produto mais saudável e sustentável, não apenas aos interessados, como também aos outros grupos de consumidores.

\section{FUNDAMENTAĈ̣̃O TEÓRICA}

\subsection{O Papel do Design para uma Humanidade Sustentável}

A sociedade atual vive em uma dependência crescente de inúmeros objetos. Manzini (2008, p. 39) diz que a percepção e a expectativa de bem estar, atualmente, estão associadas "à uma disponibilidade sempre maior de 
produtos e serviços." Para satisfazer essa carência de bem estar material, a natureza e principalmente seus recursos naturais, renováveis ou não, estão sendo degradados de modo alarmante. O planeta está sendo considerado à beira de um colapso socioambiental. Seguindo esse pensamento, Hickel (2015, p. 79-80) diz,

\begin{abstract}
[...] à medida que continuarmos legitimando essa forma de fazer, e quanto mais tempo mantivermos as coisas básicas da nossa vida - bens, matérias primas, energia, comida, dentre outros - longe do escopo do nosso entendimento, mais demorará para tomarmos uma atitude contra os danos que causamos. O desenvolvimento de uma crise ecológica e a dificuldade de entender a nossa participação intrínseca nessas dinâmicas suportam a ideia crescente de que deveremos todos enfrentar alguma forma de colapso das nossas estruturas materiais e imateriais neste século, caso não nos empenhemos em repensar as relações, em relocalizar a economia, em aprofundar a democracia.
\end{abstract}

Diante disso, nota-se como o design vem contribuindo para esta situação. Tendo como premissa a função de solucionar problemas ou atender às necessidades das pessoas, a atividade do design pretende facilitar a vida dos usuários. Entretanto, o que se percebe é que essa "facilidade" é pensada apenas para o imediato. Vivemos entremeio a um amontoado de coisas descartáveis e produtos efêmeros ou com obsolescência programada. Estes têm sido projetados para serem substituídos por outros novos em um período de tempo cada vez mais curto, gerando uma enorme quantidade de rejeitos que não está sendo tratada corretamente em seu retorno a natureza, minimizando impactos ambientais.

Sobre a crise ecológica em curso, Hickel (2015) acrescenta que o papel do designer, se exercido sob o mesmo sistema antropocêntrico de valores, limita-se em como tornar "verde" os objetos de uma cultura essencialmente antropocêntrica. O design é hoje responsável por práticas e patologias insustentáveis do ponto de vista ecológico e ambiental. O design opera os processos de transformação do natural em uma miríade de sistemas e objetos e que podem promover ou danificar as condições ecológicas e assim, empobrecer ou enriquecer o viver.

Discute-se, portanto, que na contribuição humana nesse processo, tem-se uma atuação ativa ou passiva nesse sistema produtivo? Aceitamos o que nos é ofertado sem questionamentos ou somos consumidores conscientes e recusamos o que vai contra nossos valores?

Para Sanders e Stappers (2008) é o "design que pode devolver às pessoas a experiência viva da participação em processos que não se limitam apenas à materialização de objetos de consumo." A criação conjunta envolve 
também pessoas não familiarizadas aos processos de design, todo o processo criativo é feito em conjunto. "Isso cria um estado de coautoria de projetos e sonhos, em igualdade de estatura e conhecimentos, únicos e relevantes para o processo." O termo "cocriação" se refere a "qualquer ato de criatividade coletiva, como por exemplo, criatividade partilhada por duas ou mais pessoas." (apud HICKEL, 2015, p. 87-88).

Para se chegar aos produtos de design que temos ao nosso dispor, os designers se utilizaram de processos para atribuir a esses produtos a função de transmitir os aspectos da nossa cultura e nós, usuários, atribuímos a eles os significados do nosso entorno, através de nossa consciência individual e coletiva (CAPRA, 2002; MATURANA, 1988).

A solução para os problemas de nosso tempo, de acordo com Capra (1996), está em adotarmos uma mudança radical em nossos pensamentos e valores, mudança essa que venha a transformar nossa visão de mundo na ciência e na sociedade, vindo a garantir nossa sobrevivência enquanto raça humana na Terra. Entretanto, a necessidade dessa mudança de percepção ainda não foi entendida pelos grandes líderes e pessoas de influência em nossa sociedade.

\subsection{Design para Inovação Social, Comunidades Criativas e Organizações Colaborativas}

A inovação social se dá quando as pessoas ou comunidades mudam a forma com que resolvem seus problemas ou ao criar novas oportunidades. "Tais inovações são guiadas mais por mudanças de comportamento do que por mudanças tecnológicas ou de mercado" (MANZINI, 2008, p. 62-63).

A sociedade contemporânea está em constante transformação e tudo o que fazemos, desde as ações básicas do cotidiano, até as mais complexas, podem ser reformuladas com um novo artefato ou um novo modo de fazer. "Reorganizar elementos já existentes em novas e significativas combinações é uma das possíveis definições de criatividade", essa definição nos ajuda a melhor compreender o movimento tido como "comunidades criativas: pessoas que, de forma colaborativa, inventam, aprimoram e gerenciam soluções inovadoras para novos modos de vida" (MERONI, 2007 apud MANZINI, 2008, p. 64).

As comunidades criativas, segundo Manzini, geram soluções para problemas da vida cotidiana, de modo a romper com os modelos dominantes de pensar e fazer, e, sobretudo, "resultam de uma original combinação de demandas e oportunidades." (MANZINI, 2008, p. 64-65). 
Essa criatividade socialmente difusa, de acordo com Manzini (2008), está presente no design de atividades colaborativas e estas são a expressão de mudanças radicais no contexto local por desafiarem os modos tradicionais de fazer, apresentando novas alternativas que atendem ainda ao ponto de vista da sustentabilidade, assim como as novas demandas de bem-estar. Todos os participantes colaboram direta e ativamente na busca pelo objetivo pretendido pelo empreendimento.

Existem muitos casos em que essa criatividade socialmente difusa se expressa no design de atividades que podemos denominar "colaborativas". São exemplos: modos de vida em comum nos quais espaços e serviços são compartilhados (como o co-housing); [...] uma variedade de iniciativas relativas à alimentação natural e saudável (desde o movimento internacional de Slow Food até a difusão, em muitas cidades, de uma nova geração de farmers market, ou seja, "mercados de produtores"); [...] redes que unem de modo direto e ético produtores e consumidores (como as atividades do comércio justo), entre outros (SEP, 2008 apud MANZINI, 2008, p. 62-63).

Como resultado das comunidades criativas, surgem as organizações colaborativas, que, de acordo com Manzini (2008) são grupos de pessoas que colaboram entre si, respeitando os interesses privados, sociais e ambientais, buscando resolver juntas e de forma ativa as suas próprias dificuldades e reforçando assim o tecido social. O autor ainda classifica as organizações colaborativas de duas formas: serviços colaborativos, que "são serviços sociais onde os usuários finais estão ativamente envolvidos, assumindo o papel de codesigners e co-produtores do serviço" e empreendimentos colaborativos, "são empreendimentos de produção ou iniciativas de serviço que fomentam novos modelos de atividades locais, por estabelecer relações diretas com usuários e consumidores que se tornam, também, co-produtores" (MANZINI, 2008, p. 70-71).

Esses conceitos citados corroboram a constante busca pelo bemestar da humanidade, de forma que estamos quanto seres criativos sempre procurando por opções que melhorem o modo de vida que consideramos mais adequado para nós como indivíduos ou comunidade. Esse bem-estar, como dito por Vezzoli e Manzini (2007), condiz com o princípio da sustentabilidade ambiental:

[...] atitudes positivas rumo a espaços e bens compartilhados; uma preferência por alimentos biológicos, regionais e de estação; uma tendência a regenerar redes locais; e, finalmente e mais importante, coerência com um modelo de economia distribuída, que procura ser menos 
baseado em serviços de transporte e mais capaz de integrar sistemas eficientes de energia renovável" (apud MANZINI, 2008, p. 64)

A mudança para atitudes mais sustentáveis nos remontam à busca de nossas origens, conexão com a natureza e um desapego da dependência tecnológica, característica essas inerentes à uma abordagem de inovação onde o bem-estar se baseie em menos coisas e mais relações interpessoais e no qual as pessoas voltem a fazer parte das situações como foco principal.

\title{
2.3 A influência da Nossa Alimentação para a Degradação Ambiental
}

Outro problema global que afeta o meio ambiente é a forma de alimentação que temos sustentado ao longo do tempo, uma alimentação essencialmente baseada em carne, laticínios e outros alimentos de origem animal. Tem sido estabelecida uma falsa cultura de que nossa saúde depende do consumo desses alimentos em função de seus nutrientes, proteína por meio da carne, cálcio por meio do leite etc. Contudo, segundo Slywitch (2012), uma dieta ovolacto ou lactovegetariana é capaz de fornecer todos os nutrientes necessários ao organismo humano. Já a dieta vegana, ou vegetariana estrita, não oferece fontes de vitamina B12, esta deve ser obtida através de suplementos ou alimentos enriquecidos. Quando bem planejadas, como todas devem ser, "as dietas vegetarianas promovem o crescimento e desenvolvimento adequados e podem ser adotadas em qualquer ciclo da vida, inclusive na gestação e na infância." (VIDA VEG, 2018).

O autor cita ainda,

\begin{abstract}
Várias organizações internacionais de renome como a American Heart Association (AHA), a Food and Drug Administration (FDA), o Departamento de Agricultura dos Estados Unidos (USDA), a Kids Health (Nemours Foundation), o College of Family and Consumer Sciences (University of Georgia) e a Associação Dietética Americana (ADA) têm parecer favorável ao vegetarianismo, esta afirmando inclusive que os profissionais da nutrição têm o dever de incentivar aqueles que expressam intenção de se tornarem vegetarianos (SLYWITCH, 2012, p. 2).
\end{abstract}

Carus (2010) menciona que os dados do Programa Ambiental da ONU (UNEP) do ano de 2010 apontam que a produção de carne e laticínios é responsável pelo consumo de aproximadamente $70 \%$ da água doce do mundo, $38 \%$ do uso da terra e 19\% das emissões de gases do efeito estufa, estando essa, no mesmo patamar de impactos ambientais que os combustíveis fósseis, pois 
ambos crescem subitamente a partir do crescimento econômico. Os estudos apontam uma previsão de que a população mundial chegue a 9.1 bilhões de pessoas em 2050, sendo insustentável o apetite por carne e laticínios para toda essa população. Por isso, o relatório sugere que para uma redução significativa no impacto ambiental desse aumento populacional a dieta global deve mudar para uma dieta livre de qualquer produto animal. Sendo isso vital para salvar o mundo da fome, pobreza e dos piores impactos da mudança climática.

Sobre as florestas tropicais, Gonzaga (2006) menciona que praticamente metade foi destruída e transformada em pastagem. Se esta proporção tivesse sido utilizada para o cultivo de vegetais e cereais, muito mais seres humanos seriam alimentados. 100 acres de terra tem a capacidade de produzir carne para alimentar 20 pessoas. Se a mesma parte de terra fosse cultivada trigo, 240 pessoas seriam alimentadas, afirma o autor.

\subsection{O Veganismo}

A proposta do veganismo, apesar de ainda ser desconhecida por muitas pessoas, vem ganhando cada vez mais adeptos. A organização Mercy for Animals, segundo o site Agência de Notícias de Direitos Animais - ANDA (2016), divulgou que "um número crescente de pessoas tem comido cada vez menos carne ou até mesmo a substituído completamente por alimentos vegetais. Ao longo dos últimos 10 anos, o consumo de carne nos Estados Unidos diminuiu $10 \% "$.

A prática da alimentação sem carne é muito antiga e incentivada por religiões bem estabelecidas como o budismo e hinduísmo, que não permitem o consumo de carne, com o propósito de manter o corpo puro. Filósofos como Platão e Pitágoras também apoiavam a prática vegetariana (GREIF, 2002).

O veganismo além de ressaltar a necessidade de uma alimentação saudável que respeite os animais, também enfatiza a importância de preservar o solo e o uso correto da terra, para que futuras gerações não a encontrem com erosão, queimada, sem os minerais necessários para uma vida saudável. Os veganos confiam em métodos naturais (alimentação pura, ar fresco, sol, exercício etc.) ao invés de vacinas e medicamentos para manter corpo e mente saudáveis. (SCHULTE; PORTINARI; GODOY, 2011, p. 10).

Os veganos encontram dificuldades para adquirir os produtos de seu cotidiano, pois como dizem as mesmas autoras, os produtos disponíveis para este público geralmente têm preços mais elevados e poucas opções no mercado, além de serem difíceis de se encontrar. Por praticarem um consumo consciente 
buscam informações sobre os produtos que consomem: se foram testados em animais; sobre os danos ambientais causados durante seu ciclo de vida e ainda consomem menos. Assim, a maioria dos adeptos a este estilo de vida se obriga a fazer sua própria comida pela dificuldade de encontrar lugares que ofereçam essa opção.

A notícia intitulada: "Dia Mundial do Vegetarianismo: 8\% da população brasileira afirma ser adepta do estilo" de 01/10/2012, apresenta dados da pesquisa Target Group Index. Embora a pesquisa não oferecesse uma distinção entre vegetarianos e veganos, destacou que dentre as capitais, Fortaleza aparece em primeiro lugar, com $14 \%$ da população vegetariana e em segundo lugar, Curitiba, com 11\%. Esse é um número relevante de pessoas que precisa se alimentar, vestir-se e que precisam ter suas necessidades básicas atendidas com facilidade e qualidade. (DIA..., 2012).

\title{
3 PROCEDIMENTOS METODOLÓGICOS
}

De acordo com Munari (1998) o método de projeto consiste em uma série de operações ordenadas, ditadas pela experiência, para garantir o melhor resultado com o menor esforço. O presente projeto foi desenvolvido seguindo uma ordem de etapas que serão detalhadas a seguir.

O trabalho se iniciou com base na verificação de uma necessidade, na definição do problema, traçando-se os objetivos e limites. A etapa da pesquisa bibliográfica buscou em livros, periódicos e artigos publicados o embasamento para o desenvolvimento do projeto a respeito dos tópicos, a saber: veganismo; design para inovação social; comunidades criativas; organizações colaborativas.

Os dados coletados foram então analisados e partiu-se para uma pesquisa etnográfica, que segundo Silva (2011, p. 11),

\begin{abstract}
[...] tem como propósito analisar modos de vidas de grupos sociais. Trata-se de analisar significados culturais de um dado grupo. Importante destacar que não se faz pesquisa etnográfica apenas com a aplicação de questionários, sem conhecimento do grupo. Ela exige uma imersão do pesquisador no ambiente pesquisado. Este tipo de pesquisa pode ser utilizada para análise de estilos de vida, estudos de comunidades online, de tribos, entre outros grupos.
\end{abstract}

A imersão do pesquisador se deu pelo fato de o mesmo ter se tornado adepto ao veganismo, vivenciando questões pertinentes ao problema pesquisado, convivendo e discutindo demandas sobre o tema com outras pessoas veganas. Tais dados e evidências foram realizadas por meio de 
anotações com base em observações e comunicações orais. Foi observada uma baixa oferta de alimentos veganos prontos nas regiões das cidades de Toledo e Cascavel/PR. Com aproximadamente $\mathbf{4 5 0}$ mil habitantes, a oferta se restringe a estabelecimentos que oferecem alguns produtos produzidos sem a utilização de ingredientes de origem animal. Entre as duas cidades, apenas Cascavel conta com restaurantes especializados em comida vegetariana e vegana, com quatro opções. Nenhuma das duas cidades oferece alguma loja especializada em produtos veganos, apenas lojas de produtos naturais que oferecem opções veganas e pequenos produtores que produzem de forma caseira. Em diálogo com outros veganos, dessa e de outras regiões, foi enaltecida a dificuldade em adquirir tais produtos, somente nas grandes capitais é que se encontram mais opções de estabelecimentos focados nesse público.

Em continuidade, utilizou-se de questionários para coleta de dados, que segundo Silva (2011, p. 14), "é um instrumento composto por um conjunto ordenado de perguntas a respeito das variáveis que se quer analisar." Os questionários foram aplicados por meio de formulários online, ao público vegano, aos produtores veganos e lojistas de produtos veganos. Os grupos de discussão do tema veganismo foram pesquisados em grupos de interesse comum ao veganismo em uma rede social na internet na qual foi possível o contato com uma amostra do público pretendido de diferentes regiões do Brasil.

A amostra coletada foi de 50 pessoas adeptas ao veganismo, dez produtores veganos e cinco comerciantes de produtos veganos. Com os dados levantados, desenvolveu-se um mapa sistêmico para uma melhor compreensão a respeito dos atores envolvidos no processo de produção e comércio dos produtos veganos. Sobre o mapa de sistemas, Vezzoli (2010) o define como uma ferramenta de suporte de projeto e de representação gráfica, facilitando o entendimento da estrutura de um sistema, assim como dos stakeholders. Permite com mais exatidão uma visualização de como o projeto se desenvolve e facilita a resolução de problemas.

Em sequência, todos os dados coletados e analisados até o momento serviram para se definir algumas necessidades do público e os requisitos para um futuro modelo de negócio colaborativo voltado a esses atores.

\subsection{Levantamento e Análise dos Dados Coletados}

A pesquisa de campo exploratória realizada teve como enfoque as dificuldades presentes nos hábitos de consumo de pessoas veganas, assim como as rotinas comerciais de produtores e lojistas de produtos veganos. Os questionários aplicados visaram identificar as necessidades e a busca por oportunidades de empreendimentos colaborativos neste contexto do veganismo. 
Os questionários foram aplicados por meio de formulários eletrônicos (online) na plataforma do Google Docs. Divulgados em grupos de discussão do tema veganismo de uma rede social da WEB. Esta ação facilitou o acesso a pessoas de diferentes regiões do Brasil.

As questões abordadas nos questionários para consumidores veganos foram divididas em três categorias: rotina de compra de alimentos, acesso aos produtos e pontos de venda. Os questionários aos comerciantes abordavam perguntas sobre: ponto de venda, produtos ofertados, clientes e fornecedores. Já nos questionários destinados aos produtores veganos, as questões buscavam esclarecer pontos sobre: perfil do empreendimento, produtos ofertados, vendas e relacionamento com clientes e fornecedores.

Em síntese, serão apresentadas as questões de maior relevância desta pesquisa, a saber: foram aplicados três tipos de questionários, para três grupos específicos de pessoas, sendo 50 consumidores, 5 lojistas e por último, 10 produtores de alimentos veganos.

Dos consumidores veganos consultados, a grande maioria, de $94 \%$, respondeu que compra os ingredientes para cozinhar em casa. Assim como $72 \%$ disseram considerar restrito o acesso a produtos veganos em sua região. $76 \%$ dos entrevistados respondeu que prefere comprar seus alimentos de pequenos produtores. $84 \%$ também disse que precisa ir a mais de 2 lugares diferentes quando precisa comprar seus alimentos. Quando questionados se costumam comprar alimentos pela internet, $76 \%$ respondeu que não, sobre esse total 52,6\% não tiveram interesse por esse tipo de compra. E por fim, $88 \%$ consideram melhor a opção de ir até uma loja física para comprar seus alimentos ao invés de fazê-lo via internet ou smartphone.

Nas entrevistas aplicadas aos comerciantes de produtos veganos, $80 \%$ dos entrevistados respondeu ofertar somente produtos veganos em seu estabelecimento. Na pergunta sobre o tipo de público que compra os produtos veganos em seus estabelecimentos, $40 \%$ mencionou que a compra se dá exclusivamente por pessoas veganas, igualmente $40 \%$ respondeu que a compra se dá mais por pessoas que querem experimentar esse tipo de alimento. $60 \%$ disse que a maioria dos produtos veganos ofertados em seus estabelecimentos vem de pequenos produtores. Assim como 60\% também considerou a preferência dos clientes por produtos vindos de pequenos produtores em comparação com marcas já conhecidas. Na questão sobre qual o tipo de produtos é mais procurado pelos consumidores, $100 \%$ dos entrevistados apontou a opção de pratos congelados. E também todos têm dificuldade em encontrar produtores de variados tipos de produtos em suas regiões.

Nas entrevistas com produtores veganos, 70\% apontaram como sendo um empreendimento individual. $100 \%$ disse vender seus produtos diretamente para os consumidores e apenas $30 \%$ vendem para lojas que revendem seus 
produtos. 70\% também respondeu que vende somente em sua cidade. Todos os entrevistados responderam utilizar a rede social utilizada na pesquisa para divulgar sua empresa e seus produtos, e 30\% deles também utilizam panfletos. $100 \%$ dos entrevistados disse manter contato com outros produtores veganos e todos ainda consideraram ter uma relação de cooperação entre eles. Questionados sobre o que achariam de um negócio em que outros produtores veganos pudessem atuar juntos para vender seus produtos e ter maior visibilidade, todos responderam com positividade a essa ideia. Suas opiniões seguem no Quadro 1 abaixo.

Quadro 1 - Respostas qualitativas dos produtores veganos entrevistados.

\section{O QUE VOCÊ ACHARIA DE UM NEGÓCIO EM QUE OUTROS PRODUTORES VEGANOS PUDESSEM ATUAR JUNTOS PARA VENDER SEUS PRODUTOS E TER MAIOR VISIBILIDADE? COMENTE. (10 respostas)}

- "Muito bom! Além de conhecer outras pessoas desse meio, acredito que atrairia um publico maior, pessoas que já tem consciência sobre a alimentação, mas também pessoas que tem curiosidade em experimentar." (Cascavel/PR)

\begin{tabular}{l}
\hline - "É interessante a ideia de cooperativa." (São José/SC) \\
\hline - "Acharia maravilhoso. Nós produtores veganos trabalhamos e cooperamos unidos em um \\
prol comum: a não exploração animal, e quanto maior for a visibilidade do nosso trabalho em \\
conjunto, mais pessoas conseguiremos atingir e mostrar o que é o veganismo." (Porto Alegre/ \\
RS)
\end{tabular}

- "Acho fantástico. Pessoas com o mesmo proposito, quando reunidas ajudam a vibrar muito mais para que um objetivo seja alcançado e prospere. Os laços entre os produtores devem ser fortalecidos, acredito que há espaço pra todos e parceria é essencial." (Belo Horizonte/MG)

- "Eu acho muito importante isso, pois nos ajudamos e incentivamos outros produtores fazendo com que os produtos fiquem mais acessíveis. Gosto da ideia de colaboração. É isso que acontece na Cooperativa Vegana que participo, somos em 3 colaboradores agora." (Florianópolis/SC)

- "Interessante, desde que atendesse aos anseios cooperativos em todas as pontas da cadeia." (Florianópolis/SC)

- "Acharia excelente! Acredito no empreendimento sustentável com atuação colaborativa. No caso do meu micro empreendimento, ainda não chegamos a implantar tais mecanismos para atuar de forma colaborativa (já que ainda está no meio familiar), mas temos no nosso projeto criar cozinha colaborativa onde possam ser realizados cursos, podendo disponibilizar espaço para criação e desenvolvimento de produtos veganos, assim como promover o aprendizado de técnicas gastronômicas e novas receitas." (Florianópolis/SC)

- "Acho ótima, toda forma de propagar o veganismo, de salvar a vida e diminuir a exploração animal é super válida." (Bauru/SP)

- "Isso ocorre em diferentes feiras organizadas na cidade. Acho sempre uma excelente oportunidade para aproximar os produtores e clientes." (Curitiba/PR)

- "Acho ótimo, juntos teremos mais poder de alcance e o ideal do veganismo ganhará forças." (Curitiba/PR)

Fonte: Elaborado pelos autores.

Com o desenvolvimento deste projeto se espera chegar a uma proposta de serviço que atenda às necessidades do público alvo, consumidores veganos, em primeira instância e que ainda sirva como um meio de divulgação da filosofia 
vegana para o restante da população, fazendo crescer o interesse sobre esse estilo de vida e difundindo o consumo de produtos/alimentos mais saudáveis e sustentáveis.

Para tanto, utilizou-se a ferramenta de mapa de sistemas ou mapa sistêmico, que, segundo Vezzoli (2010), tem a finalidade de ajudar o codesign e a visualização da estrutura do sistema abordado. Essa ferramenta destaca gráfica e visualmente os atores socioeconômicos, primários e secundários, envolvidos em um sistema, assim como suas diferentes interações, sejam elas fluxos de materiais e/ou produtos, informação, dinheiro, trabalho, pessoas.

A Figura 1 demonstra graficamente e em síntese a estrutura sistêmica, verificada nas pesquisas de campo e nas literaturas consultadas e citadas, em que os atores foram divididos em produtores veganos (pequenas empresas ou produtores individuais especializados na produção de alimentos veganos); comerciantes (lojistas que vendem produtos veganos em seus estabelecimentos que podem ser exclusivamente veganos ou mistos, que vendem outros tipos de produtos); e consumidores (pessoas que consomem alimentos veganos, que podem ou não ser veganos, como intolerantes/alérgicos a produtos de origem animal, pessoas interessadas em uma dieta mais saudável ou ainda em experimentar esse tipo de alimento.

Desse modo, o mapa sistêmico esboça a correlação entre os atores, associando-os aos termos apresentados nessa pesquisa. A manufatura de produtos veganos parte de uma comunidade criativa, sendo esse o ponto de partida de uma nova ideia para a sociedade resultante de um problema da vida cotidiana, a dificuldade em comprar alimentos veganos. A ideia de organizações colaborativas entra para aperfeiçoar o trabalho dos produtores veganos, como diz Manzini (2008), esses grupos colaboram entre si e buscam resolver juntos e de forma ativa as suas próprias dificuldades. A fim de formar uma organização colaborativa, um número " $x$ " de produtores se integraria colaborativamente para trabalhar em conjunto e apoiando uns aos outros para melhor solucionar seus problemas e ampliar as possibilidades de crescimento e alcance comercial. O design para inovação social inserido na gestão do design tem o papel, nesse sistema, de auxiliar na identificação de problemas em todos os setores e estágios do processo, buscar soluções, além de propor medidas sustentáveis para o empreendimento, seja na aquisição de matéria-prima, no processo produtivo, nas formas de venda, ou na destinação de sobras da produção e embalagens. O mapa sistêmico apresentado mostra o processo em um ciclo que se mantém ativo e constante, representando o conceito colaborativo e de coprodução, no qual todos os atores do sistema mantém uma relação direta entre eles e o produto final e são responsáveis, como consequência, por promover a inovação social, que se dará por ter facilitado o acesso a produtos veganos, proporcionado mais visibilidade a produtores veganos e ajudado a difundir esse estilo de vida mais saudável e sustentável. 
Figura 1 - Mapa sistêmico de produtos veganos.

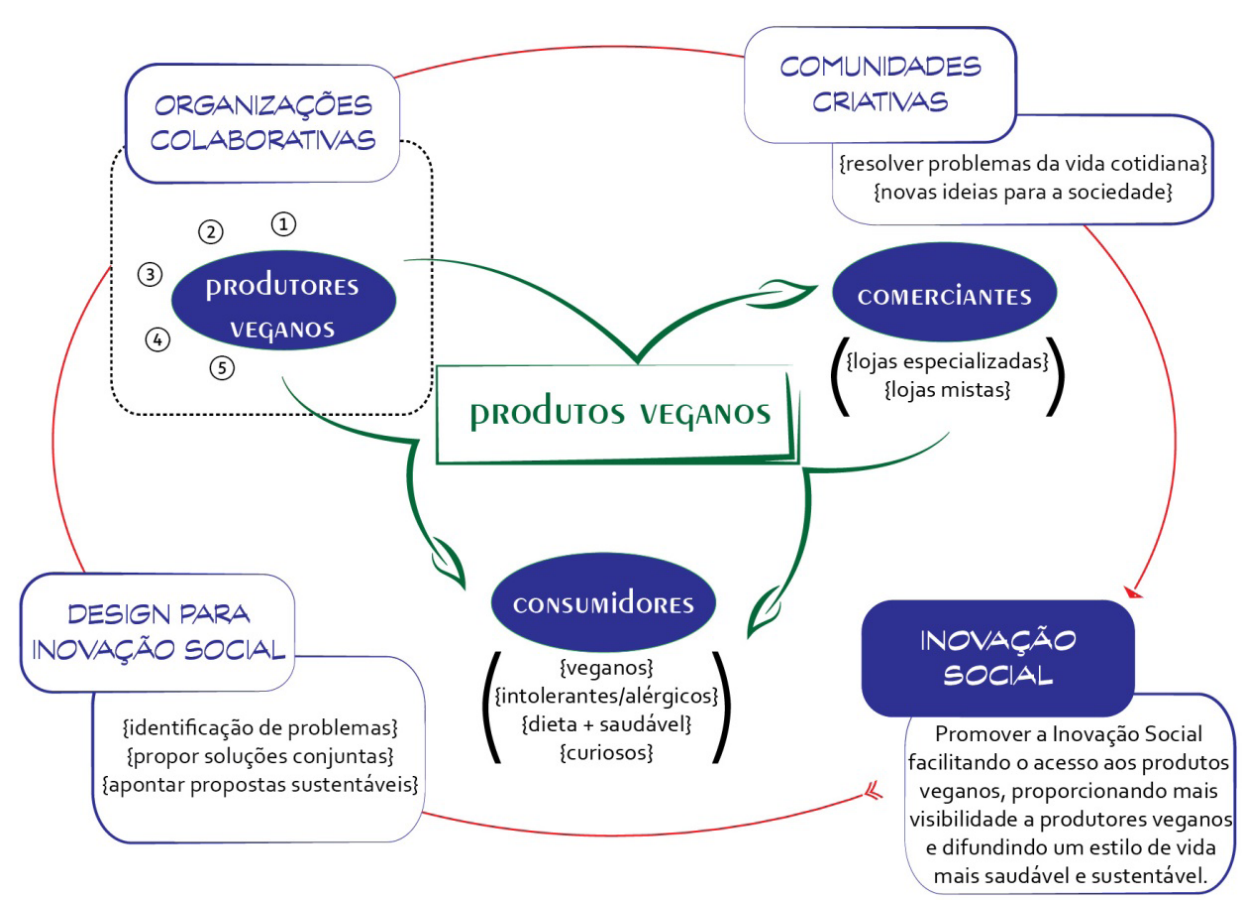

Fonte: Elaborado pelos autores.

O mapa sistêmico apresentado visa uma integração entre os atores envolvidos, de modo que se propõe a associação dos pequenos produtores veganos locais em uma organização colaborativa para facilitar a inserção social dos mesmos, trazendo maior notoriedade comercial, por meio da colaboração do design para inovação social.

A integração entre os atores pode ser proporcionada por um aplicativo de smartphone que promova a interatividade e colaboração entre eles. Uma plataforma colaborativa que possa facilitar a comunicação entre os envolvidos na organização em questões de encomendas, reposição de produtos nos pontos de vendas, pagamentos, pendências e promoções.

\section{$5 \quad$ RESULTADOS E DISCUSSÃO}

Com base nas pesquisas e levantamentos realizados, constatou-se que os produtores veganos locais são, em sua maioria, pequenas empresas familiares ou individuais, com pouca estrutura ou suporte, o que dificulta que os mesmos tenham visibilidade no mercado e a prospecção de novos clientes. No que tange aos consumidores veganos, estes apontaram ter dificuldades em encontrar diversidade de produtos alimentícios em suas localidades, tendo que se deslocar a diferentes locais para adquirir seus alimentos. Com base nessas informações esboçou-se um mapa sistêmico dos produtos veganos para ressaltar cada ator envolvido no processo, assim como seu papel fundamental neste sistema. 
Como mostrado no texto, Manzini (2008) fala de empreendimentos colaborativos como novos modelos de atividades locais, onde a relação com usuários e consumidores é direta por fazerem parte de um espaço geográfico próximo, e estes se tornam coprodutores no processo. Sendo assim, propõese uma organização colaborativa de pequenos produtores veganos como alternativa para enfrentar as dificuldades apontadas. De modo conjunto, produtores de uma mesma localidade possam produzir, vender e divulgar seus produtos.

Ao trabalhar colaborativamente os produtores terão mais força em suas ações, poderão reduzir os gastos organizando compras conjuntas de matériasprimas, embalagens, equipamentos e contarão com mais meios para divulgar seus produtos. Como desdobramento futuro, propõe-se o desenvolvimento de um aplicativo para smartphone que venha auxiliar a comunicação entre os comerciantes e produtores, visando facilitar os pedidos e reposições dos produtos nos pontos de venda.

A implantação deste projeto poderá atuar no campo da inovação social ao proporcionar construção de conhecimentos e ampliação do fluxo de informações a estes produtores, possibilitando o incremento no mercado consumidor vegano na região. A promoção da consciência alimentar do estilo de vida vegano a mais pessoas é verificada como um processo de longo prazo que de acordo com os preceitos da sustentabilidade contribuirá com as gerações presentes e futuras.

\section{CONSIDERAC̣õES}

Diante do atual panorama socioambiental em que se encontra o planeta, faz-se urgente a tomada de medidas de manutenção ou reestabelecimento do equilíbrio entre o homem e natureza.

Como apresentado no decorrer deste trabalho, a alimentação baseada em carne, laticínios, ovos e demais subprodutos de origem animal é uma das principais causas do desmatamento e poluição, além de demandar uma considerável quantia de água doce em seu processo produtivo. O veganismo, por sua vez, pregando a não exploração animal, é uma prática que exclui todos os produtos de origem animal tanto na alimentação, como em todos os aspectos do cotidiano, sendo uma alternativa extremamente sustentável e ética.

Com foco na alimentação vegana, buscou-se, por meio de questionários, compreender as dificuldades apontadas por consumidores, comerciantes e produtores de alimentos veganos, assim como buscar por oportunidades em que a gestão do design pudesse contribuir, de modo sustentável, para o desenvolvimento de empreendimentos voltados para o público vegano. 
WEISS, Marco Antonio; CAVALCANTE, Ana Luisa Boavista Lustosa; FIGUEIREDO, Luiz Fernando Gonçalves de

Assim, a proposta de uma organização colaborativa entre os pequenos produtores veganos pode proporcionar maior visibilidade aos mesmos e, com a assistência da gestão do design, promover a inovação social ao difundir o estilo de vida vegano e levar a uma consciência alimentar mais saudável e sustentável, de acordo com o veganismo.

Como propostas para estudos futuros, faz-se relevante criar estratégias para aproximação dos produtores locais e comerciantes, bem como uma plataforma integradora dos stakeholders que venha a concretizar o estudo proposto pelo artigo. 


\section{REFERÊNCIAS}

AGÊNCIA DE NOTÍCIAS DE DIREITOS ANIMAIS - ANDA. Seis fatos que revelam o avanço do veganismo no mundo. 2016. Disponível em: http://www. anda.jor.br/23/05/2016/seis-fatos-que-revelam-o-avanco-do-veganismo-nomundo. Acesso em: 22 ago. 2016.

CAPRA, Fritjof. A teia da vida: uma nova compreensão científica dos sistemas vivos. São Paulo: Coltrix, 1996.

CAPRA, Fritjof. The hidden connections. London: Flamingo, Harper Collins, 2002.

CARUS, Felicity. UN urges global move to meat and dairy-free diet. 2010. Disponível em: http://www.guardian.co.uk/environment/2010/jun/02/unreport-meat-free-diet. Acesso em: 6 jan. 2016.

DIA mundial do vegetarianismo: $8 \%$ da população brasileira afirma ser adepta do estilo. Ibope, 1 out. 2012. Disponível em: http://www.ibope.com.br/pt-br/ noticias/paginas/dia-mundial-do-vegetarianismo-8-da-populacao-brasileiraafirma-ser-adepta-ao-estilo.aspx. Acesso em: 28 ago. 2016.

GONZAGA, Fernando. Cozinha vegetariana: a alternativa saudável. São Paulo: Impala, 2006.

GREIF, Sérgio. Sustentabilidade econômica e ecológica mediante opção pelo vegetarianismo. Caderno de Debates, Campinas, v. IX, p. 55-68, 2002.

HICKEL, Denis Kern. O design como a expressão de fazer as coisas juntos: um entendimento ecológico. Projética, Londrina, v. 6 n. 1, p. 77-96, jul. 2015.

MANZINI, Ezio. Design para a inovação social e sustentabilidade: comunidades Criativas organizações colaborativas e novas redes projetivas. Rio de Janeiro: E-papers, 2008.

MATURANA, Humberto. Ontology of observing: the biological foundations of self consciousness and the physical domain of existence. In: AMERICAN SOCIETY FOR CYBERNETICS CONFERENCE, 1988, Felton, CA, USA.

Disponível em: http://ada.evergreen.edu/ arunc/texts/ cybernetics/ oo/oo3. pdf. Acesso em: 10 fev. 2014. 
SANDERS, Elizabeth B.-N.; STAPPERS, Pieter J. Co-creation and the new landscapes of design. CoDesign: International Journal of CoCreation in Design and the Arts, UK, v.4, n.1, p. 5-18, 2008.

SCHULTE, Neide; PORTINARI, Denise; GODOY, Ilma. Ser e viver o veganismo: proposta para o design da humanidade sustentável. In: SIMPÓSIO INTERDISCIPLINAR DO LARS: PALAVRAS E COISAS, 9., 2011, Rio de Janeiro. Anais [...]. Rio de Janeiro: PUC, 2011. p. 15-20.

SILVA, Eli Lopes da. Manual de elaboração de trabalhos acadêmicos: graduação e pós-graduação. Florianópolis: SENAC/DR. 2.ed. 2011.

SLYWITCH, Eric. Guia alimentar de dietas vegetarianas para adultos. Florianópolis: Departamento de Medicina e Nutrição, Sociedade Vegetariana Brasileira, 2012.

VEGANISMO. Sociedade Vegana, set. 2011. Disponível em: http:// sociedadevegana.org/textos-fundamentais/veganismo/. Acesso em: 28 ago. 2016.

VEZZOLI, Carlo. Design de Sistemas para a sustentabilidade: teorias, métodos e ferramentas para o design sustentável de "sistemas de satisfação". Salvador: EDUFBA, 2010.

VIDA VEG. Por que escolher alimentos veganos? Disponível em: https:// vidaveg.com.br/. Acesso em: 28 jun. 2018

Data de submissão: 2017-05-03

Data de aceite: 2018-08-01 